\title{
LOS BORRADORES DE PIERRE MENARD
}

Según he mostrado ya ${ }^{1}$, Borges dedicó a Cervantes muchas páginas críticas y lo mencionó a menudo en sus escritos. Muchos de esos comentarios repiten la bien conocida definición del propósito de Cervantes como oponer a la idealización típica de los libros de caballería, la novela de caracteres. Más original es la afirmación de Borges de que Cervantes continuaba entre tanto amando los libros caballerescos, amor que incluyó de algún modo en el Quijote, que resulta pues la última y la mejor novela caballeresca. (En vista de lo cual, no sorprende la intepretación romántica del proyecto de Alonso Quijano.)

Debe notarse al mismo tiempo que, aunque Borges elogia en una ocasión la misteriosa eficacia del estilo "oral" de Cervan$t^{2}{ }^{2}$, tiene de él una opinión que choca por lo negativa, pues lo considera totalmente imperfecto de acuerdo con las normas retóricas $^{3}$. Borges cree asimismo que la Primera parte del Quijote es inmensamente inferior a la Segunda ("cargosa", la llama) , y

1 “El Quijote según Borges", NRFH, 36 (1988), 477-500, y "Nota adicional sobre Borges y el Quijote", NRFH, 39 (1991), 1067-1070.

2 "Nota preliminar", Novelas ejemplares, Emecé, Buenos Aires, 1946, p. 10.

${ }^{3}$ Dice en la "Nota" recién citada que el estilo cervantino "abunda en repeticiones, en languideces, en hiatos, en errores de construcción, en ociosos o perjudiciales epítetos, en cambios de propósito" (p. 10); todo ello "atemperado" o "anulado" por su "encanto especial" (ibid.) En un artículo anterior ("La supersticiosa ética del lector", Discusión, 1932) declara el estilo de Cervantes defectuoso en extremo, apoyándose en Lugones y Groussac (es pobre de color, inseguro de estructura, repetitivo, desaliñado, grandilocuente), pero celebra el modo como Don'Quijote, porque no aspira a que sus palabras, de tan perfectas, no puedan ser alteradas, sobrevive a las traducciones y las versiones más descuidadas.

${ }^{4}$ Gracias a sus "cargosas retahílas de palos y puñetazos"' ("La conducta 
critica también la oposición de personalidades del hidalgo y su escudero como un procedimiento que resta verosimilitud a la obra $^{5}$.

La única utilización del Quijote en los cuentos publicados de Borges tiene lugar en "Pierre Menard, autor del Quijote", de 1939, incluido en la primera edición de Ficciones (1944; la primera parte apareció en 1942 como El jardín de senderos que se bifurcan), uno de sus primeros y más originales relatos. "Pierre Menard"' es probablemente el texto de Borges que más ha contribuido a establecer su reputación como "postmodernista", gracias, principalmente, al artículo de 1964 del influyente crítico francés Gérac Genette $^{6}$. (Ya antes el escritor Maurice Blanchot había tratadc de "Pierre Menard" en Le Livre à venir, de 19597.)

Genette discute en ese artículo, citando principalmente ensa yos de Borges y el cuento "Tlón, Uqbar, Orbis Tertius", ante de concentrarse en "Pierre Menard", el "mito" de la unidad d la literatura planteado en ellos por su autor. Aquélla aparece co mo "un espacio homogéneo y reversible en el que las particulari dades individuales y los datos cronológicos no tienen cabida"' " una vasta creación anónima donde cada autor no es más qu la encarnación fortuita de un espíritu intemporal e impersonal" que "habita la aparente pluralidad de los autores y las obras (p. 205). El creer que "una obra está esencialmente determinad por su autor y en consecuencia lo expresa" es un "prejuicio que "empobrece el comercio de las letras" (p. 207). Genette pri

novelística de Cervantes', El idioma de los argentinos, M. Gleizer, Buenos A res, 1928, p. 141).

5 "Esa discordia tan simétrica y persistente acaba por quitarles realida por disminuirlos a figuras de circo" ("Sobre The Purple Land", Otras inquisic nes, Alianza Editorial, Madrid, 1979, p. 138. [1a. ed. 1952]). (Todas las ci provienen de esta edición.)

${ }^{6}$ GÉRard Genette, “La littérature selon Borges", L'Herne, 196 pp. 323-327; una segunda versión del mismo artículo, como " $L$ 'utopie lit raire", en Figures. Essais, Seuil, Paris, 1966, pp. 123-132; incluido en JAI Alazraki (ed.), Jorge Luis Borges, Taurus, Madrid, 1976, pp. 203-210. (] das las citas provienen de esta versión.) Para una discusión del ensayo . Emir Rodríguez Monegal, "Hacia la lectura como escritura", en Bor hacia una lectura poética, Guadarrama, Madrid, 1976, pp. 102-105, y "Bor y la "nouvelle critique»", RevIb, 38 (1972), 367-390; recogido en JAIME A ZRAKI (ed.), op. cit., pp. 267-287.

7 Ver "El infinito literario: El aleph", en Jaime Alazraki (ed.), op. । pp. 211-214.

8 "La utopía literaria", ibid., p. 205. 
fiere, en cambio, considerar que el autor "is nothing in himself"' (según dice Borges de Shakespeare, citando a William Hazlitt)" y situar en el primer plano al lector, negando que el autor "detente" (p. 208) sobre su obra ningún privilegio, ya que, por lo mismo que no hay una sola fábula que sea original, toda obra es universal.

La vida de un texto literario, concluye Genette apoyándose en citas de Borges, comienza de hecho con el acto de la lectura y las transformaciones que la memoria de sus lectores operan sobre aquél. Un libro no es algo concluido, sino un depósito de formas que aguardan constantemente un significado que es también siempre cambiante (p. 210). Las observaciones de Genette expresan algo que sabemos desde siempre, a saber, los libros, puesto que se escriben para ser leídos, no completan su existencia hasta que pasan a las mentes de los lectores que transformarán el significado que quisieron darles sus autores. Éstos, por lo tanto, no lo son sino parcialmente. Estas ideas son intrínsecas al concepto de intertextualidad: ciertos lectores escribirán libros dentro de los cuales se insertarán los textos que han leído, no a través de la "influencia" directa o consciente que puedan haber tenido en el escritor, sino más sutilmente, a través de su fluido, cambiante significado en la memoria. Cada libro es la memoria de todos los libros, y se define no de modo inmanente, sino por oposición, mediante sus diferencias respecto a los demás libros. La interpretación que hace Genette del sentido de la obra de Borges ("la utopía que nos propone la literatura según Borges", p. 209) reafirma el ahistoricismo característico del modernismo y del postmodernismo: los cambios en el significado de un libro a través del tiempo tienen lugar sólo por el influjo de otros libros y fuera de la historia.

La consecuencia final de esa "utopía" es hacer de todos los autores uno, de todos los libros un solo libro, y de cada libro todos los libros. En el planeta inventado Tlón ("Tlón, Uqbar, Orbis Tertius" es de 1941, dos años posterior a "Pierre Menard") "se ha establecido que todas las obras son obra de un solo autor, que es intemporal y es anónimo" 10 , y un poco antes se dice que, al igual que todos somos, en el "vertiginoso instante del coito", p. 145.

9 Ibid., p. 208. Ver además "De alguien a nadie", Otras inquisiciones,

10 “Tlön...", Ficciones, Emecé, Buenos Aires, 1958, p. 27. (Todas las citas provienen de esta edición.) 
el mismo, también "Todos los hombres que repiten una línea de Shakespeare, son William Shakespeare" (p. 25, n. 1). Somos, o, más bien, nos convertimos en aquello que leemos; le literatura es propiedad de todos los lectores. En el ensayo " $\mathrm{L} \hat{c}$ flor de Coleridge", de 1945, Borges introduce la teoría, enuncia da por Emerson y Valéry, de que la historia de la literature no debería ser la de los autores y sus carreras, sino la del Espíritı como productor y consumidor de literatura, de modo que esi historia podría hacerse sin mencionar un solo autor ${ }^{11}$. El con cepto de un autor único cuyas muchas obras podrían concebirst como un solo texto compuesto por todos los escritores del mund، satisface a la vez la creencia panteísta en la unidad del espíritı creador, la cual concibe la pluralidad como ilusión, y el despre cio típicamente clasicista por la originalidad, destinado a subra yar la superioridad de la tradición sobre el talento individue del escritor.

Al igual que "El acercamiento a Almotásim", de 1935 "Pierre Menard" imita la estructura de una reseña, en su cas la de la obra completa de un escritor ficticio, la cual "no es arbi traria [sino] un diagrama de su historia mental"12. Menard $\epsilon$ un erudito que escribe principalmente sobre problemas de 1 filosofía, la lógica y la retórica a partir de la obra de otros autc res, muchos de ellos mal conocidos; también ha escrito poesía hecho algunas traducciones del castellano. Su obra refleja a a guien extremadamente culto, inteligente, sensible, quien prefies escribir sobre otros a buscar su propia voz. Esta actitud es aplici ble también a su obra "invisible", la escritura de dos capítule -el noveno y el trigésimo octavo de la Primera parte- y u fragmento de otro - el vigésimo segundo, no se aclara de qu parte- del Quijote. Esa obra, "tal vez la más significativa c nuestro tiempo"13, apunta el autor del artículo-memoria-cues to, un amigo de Menard, consiste en la escritura, palabra por $\mathrm{p}$ labra, del texto cervantino, el cual Menard no copió, sino escı bió como suyo.

Menard no quería componer "otro" Quijote, transponienc la obra maestra, como se ha hecho tantas veces, a un ambien moderno, sino quería escribir líneas que coincidieran (este verl es la clave de su propósito) exactamente con las de Cervantc

\footnotetext{
11 Otras inquisiciones, p. 11.

12 Prólogo, Ficciones, p. ii.

13 "Pierre Menard, autor del Quijote", Ficciones, p. 48.
} 
Para alcanzar su propósito Menard ideó inicialmente una identificación total con Cervantes (la cual incluiría recuperar el castellano del siglo Xvir y olvidar la historia de Europa entre 1602 y 1918 - la fecha, al parecer, del comienzo de su proyecto), pero descartó el método por demasiado fácil y poco interesante para lograr algo imposible por definición. Así que decidió continuar siendo Menard a la vez que el autor del Quijote, sin mirar ni una sola vez ese texto. La dificultad de la tarea de Menard la subrayan los miles de borradores que quemó, pues no quería que nadie viese sino los capítulos definitivos. Su tarea era imposible, según le explicó a su corresponsal, el supuesto autor del texto que discutimos, tan sólo porque se necesitaría ser inmortal para concluirla; de lo contrario no sería "esencialmente difícil" (p. 51). (Si Menard murió en 1939 - la fecha del cuento-, y empezó su Quijote en 1918, trabajó en él veinte años. Su última obra fech?da es de 1934, así que es de presumir que entre esa fecha y la de su muerte debió dedicarse exclusivamente a su Quijote.)

Contrariamente a lo que cabría suponer, a Menard no le gustaba el Quijote. Lo había leído "tal vez enteramente" (p. 52) a los doce o trece años (lo mismo que Borges, seguramente), y no lo consideraba "inevitable" (p. 51) para que el mundo (es decir, para que la literatura universal) fuese lo que es, sino, de hecho, "contingente", "innecesario" (p. 52). Tras aquella lectura preadolescente, Menard había vuelto al Quijote de vez en cuando: "Después he releído con atención algunos capítulos, aquellos que no intentaré por ahora" (ibid.). Menard había también "cursado" (ibid.) (el verbo implica una lectura hecha por obligación) las demás obras de Cervantes. Para el momento en que Menard escribe a su amigo en 1934, su memoria de Don Quijote se había "simplificado" a través del olvido y la indiferencia, convirtiéndose en "la imprecisa imagen anterior de un libro no escrito" (ibid.).

Lo que Menard desea demostrar es que todos los hombres - $\mathrm{o}$ al menos todos los hombres inteligentes y bien educadosson capaces de recrear todos los libros que estimamos como clásicos, quizá absolutamente todos los libros. "«Pensar, analizar, inventar [...] no son actos anómalos, son la normal respiración de la inteligencia. Glorificar el ocasional cumplimiento de esa función, atesorar antiguos y ajenos pensamientos, recordar con incrédulo estupor lo que el doctor universalis pensó, es confesar nuestra languidez o nuestra barbarie. Todo hombre debe ser capaz de 
todas las ideas y entiendo que en el porvenir lo será»" (p. 56) ${ }^{14}$. Lo cual confirma Herbert Quain, de "Examen de la obra de Herbert Quain" (1941, incluido en Ficciones), quien cree "que los lectores eran una especie ya extinta. No hay europeo [...] que no sea un escritor, en potencia o en acto"15. La tesis de Menard que su "obra maestra" demuestra ignora el papel de la imaginación, el más individual de los factores que intervienen er la creación artística, en favor de la educación y, sobre todo, de lé memoria, pero una memoria no libre, sino dirigida.

A través de los textos que plantean el autor único y de los que tratan del corolario de esa tesis, el que todos podemos escribir to dos los libros, Borges está sugiriendo la unidad básica del pensa miento occidental. La cual expresa a través de la metáfora de li escritura: todos los europeos educados - y por extensión los des cendientes de europeos - escriben el mismo texto cultural; c mismo espíritu, por lo tanto, domina su pensamiento, el cue Borges traduce como discurso literario. El rechazo de la autorí individual por medio de hacer de todos los europeos, sus descer dientes y quienes viven dentro de la cultura europeo-occident: lectores-escritores del mismo texto, sirve indirectamente par proteger a éste de la interferencia de elementos ajenos a su propi contexto cultural: no occidentales, populares, tercermundista: femeninos. (Esa suerte de idealización del Libro es independier te, según demuestra el caso de Menard respecto al Quijote, c consideraciones estéticas y relaciones afectivas.) El texto europt de Menard, inmóvil en un tiempo que es ilusión ${ }^{16}$, obra c lectores-escritores que están perennemente re-leyéndolo o re-e cribiéndolo - términos intercambiables aquí-, queda aislado c transformaciones sociales y resulta totalmente ahistórico. Nót se, sin embargo, que tal inmovilidad cuestiona el papel de la $\mathrm{m}$ moria en la transformación de la literatura, y de ésta como des

${ }^{14}$ Esta afirmación recuerda el modo como los hombres del futuro, "Utopía de un hombre que está cansado" (El libro de arena, 1975), "debe producir por su cuenta las ciencias y las artes que necesita[n]", a lo que visitante del presente agrega: "En tal caso, cada cual debe ser su propio B nard Shaw, su propio Jesucristo y su propio Arquímedes" (El libro de are Emecé, Buenos Aires, 1975, p. 130).

${ }^{15}$ Ficciones, p. 83.

16 Ver "Nueva refutación del tiempo" (1947-1946), de Otras inquisicio así como los ensayos sobre el tema del tiempo incluidos en Historia de la ete dad (1936 y 1953). 
nada a ser transformada por los lectores, según lo planteaba Genette pero niega, de hecho, el Quijote de Menard.

La identidad absoluta entre éste y el cervantino va dirigida a probar que, al igual que cualquier otro libro, el Quijote no es sino la manifestación de cierta capacidad intelectual alcanzable, de propornérselo, por cualquier hombre educado que posea los instrumentos intelectuales necesarios. Creemos que el Quijote es de Cervantes, pero también podría haber sido de Menard. De modo que su amigo lee ahora el Quijote "como si lo hubiera pensado Menard" (p. 51), y reconociendo su estilo "arcaizante" (p. 55) en las frases cervantinas, concluye que su Quijote es más "sutil" (p. 53), pues aunque escoge como su realidad la tierra de Carmen en el siglo de Lope y de Lepanto, evita la españolada. El texto de Menard es también más complejo, como cuando, contra lo que debería esperarse de un intelectual, falla el pleito entre las armas y las letras a favor de las primeras o, no obstante que escribe en el siglo $x x$, afirma que la historia es la madre de la verdad (I, 38 y 9 ).

La re-escritura del Quijote por Menard es, de hecho, un ejercicio deconstructivo: si consigue apropiarse el Quijote, el crítico probará que carece de un principio estructurante interno que proviene de Cervantes. Excepto que el proyecto de Menard, porque no emplea una memoria transformadora y creadora de diferencias entre los textos, termina trayendo al primer plano al texto mismo de Cervantes como absoluto y centro originador de sentidos. Porque lo que Menard hace es reproducir el Quijote en lugar de reflejar el flujo permanente de un texto que no tiene autor, sino sólo lectores. Es natural que alguien con un temperamento tan sofisticado como Menard desprecie por vulgares las versiones modernas ("parasitarias", p. 49, las llama) del Quijote. Su tarea, sin embargo, se dirige a conseguir que a través de miles de borradores ("Multiplicó los borradores; corrigió tenazmente y desgarró miles de páginas manuscritas', p. 56 ${ }^{17}$ ) compuestos sobre la base de un recuerdo del texto original que, por más que vago inicialmente, debe irse precisando a través de esos borradores, su

17 A estas frases sigue una nota al pie: "Recuerdo sus cuadernos cuadriculados, sus negras tachaduras, sus peculiares símbolos tipográficos [...] le gustaba salir a caminar por los arrabales de Nîmes; solía llevar consigo un cuaderno y hacer una alegre fogata' (p. 56). 
escritura termine coincidiendo - como por azar si no fuese por aquéllos - con la de Cervantes en el Quijote ${ }^{18}$.

Genette cree que Menard "es el autor del Quijote por la razón suficiente de que todo lector (todo verdadero lector) lo es"'19, le cual "confirmaría" el modo como lee ahora su corresponsal e] Quijote de Cervantes. Esa lectura, sin embargo, aun si con un esfuerzo hacemos caso omiso del humor con que se la describe (e' estilo de Menard es de por sí arcaizante; evita la españolada etc.), no implica que los sentidos del Quijote original se hayan al. terado, sino que algunos de ellos, característicamente renacentis. tas y hasta medievales, han perdido su validez. Menard no ha al terado esos significados, por lo tanto, sino que al atribuírselos er 1930, llama la atención sobre su dependencia de ciertos valores de cierto epistema finiquitado. Lo cual no hace su obra más suti y compleja que la de Cervantes, sino absurda, porque no se h: independizado en lo más mínimo de la de éste. El único mod، de leer el Quijote de Menard es desde la perspectiva del cer vantino.

Para ser efectivamente el manifiesto postmodernista y el ata que al logocentrismo característico de nuestra cultura que, a par tir de los ensayos de Blanchot y de Genette, se supone que se este maravilloso cuento, Menard tendría que haber dejado traba jar al azar a través de su memoria mientras componía, sobre s impreciso recuerdo del Quijote cervantino, un sistema -o má bien a-sistema - de diferencias ${ }^{20}$ que repitieran, sin proponers una identidad inalcanzable por definición, cierto núcleo de sign ficados que se halla, también por definición, ausente del Quijo original. El cual, de acuerdo con la tesis de Menard, no es ni or ginal en relación con la literatura universal, ni de Cervantes sin casualmente, pues pertenece a ese espíritu productor y consum dor de toda la literatura.

18 Uno de los capítulos del Quijote de Menard (I, 9) es representativo c su empresa. Allí Cervantes introduce al "verdadero" autor de su libro, B nengeli, cuya obra hace traducir, consiguiendo de ese modo distanciarse , su texto para subrayar su naturaleza cómica, así como que es ficción en $\mathrm{v}$ de historia. También Menard desea separarse del texto cervantino afirman que no es sino palabras entretejidas que la memoria puede recrear en el $\mathrm{m}$ mo orden en que aparecen en el original. TAMARA Holzapfel, en "Apum para una lectura del Quijote de Menard"' (RevIb, 43, 1977, 671-677), trata justificar en relación con su proyecto la selección por Menard de los otros c pítulos del Quijote que re-escribió.

19 "La utopía literaria", p. 210.

20 Ver JacQues Derrida, L'écriture et la différanc:, Seuil, Paris, 1967. 
Sólo que Borges no se proponía verdaderamente con "Pierre Menard", negar el Quijote. Su intención era otra: desarrollar como estructura narrativa, para luego ridiculizarlo, un ábsoluto, el postulado por Valéry (de quien es lector Menard) ${ }^{21}$ a propósito de que todas las obras literarias son de un solo autor. Esa tesis y el supuesto logro de Menard niegan, de paso, "la ley fundamental" 22 de la biblioteca de Babel, a saber, "No hay, en la vasta biblioteca, dos libros idénticos" (p. 89), aunque sí haya, puesto que se encuentran en ella todas las combinaciones posibles de los símbolos ortográficos expresando cuanto es dable expresar, "centenares de miles de facsísmiles imperfectos" (p. 92) de cada obra. Menard, sin embargo, evita la variante, evita incluso dejar prueba de haberse alejado ni por una coma del texto de Cervantes. Con lo cual se hace imposible eliminar la presencia de éste en el nuevo texto. Al fusionarse con el de Cervantes, el Quijote de Menard queda identificado como de Cervantes; la obra maestra de aquél, lamenta su amigo, resulta invisible, pues nadie reconoce en esos capítulos de su Quijote la pluma de Menard, sino que los confunden con los cervantinos ${ }^{23}$.

En consecuencia, el Quijote de Cervantes reocupa al final con más fuerza que nunca el espacio del que Menard intentó desplazarlo como texto y como unidad significativa ${ }^{24}$. Los comentarios

21 El catálogo de la obra "visible" de Menard comienza con un "soneto simbolista" ("Pierre Menard...", p. 46) y su corresponsal lo llama "un simbolista de Nîmes" (p. 51). También incluye su obra "una trasposición en alejandrinos del Cimetière marin de Paul Valéry" (p. 47), y "Una invectiva" (id.) contra éste que "es el reverso exacto de su verdadera opinión", de modo que "la antigua amistad entre ambos escritores no se alteró" (p. 48). La invectiva se explica por el "Hábito resignado o irónico [de Menard] de propagar ideas que eran el estricto reverso de las preferidas por él" (p. 54). NORA Marval de Mcnatr, en " "Pierre Menard, autor del Quijote»: Huellas y sentido" (Homenaje a Humberto Piñera, Playor, Madrid, 1979, pp. 159-165), nota la relación entre el cuento de Borges y el personaje de Valéry Monsieur Teste (mencionado en "Pierre Menard" en relación con el simbolismo, p. 51), quien había decidido vivir sólo con el intelecto, excepto que por veinte años no había leído ni escrito nada, para que ni las palabras de otros ni las propias interfiriesen con el fluir del pensamiento.

22 "La biblioteca de Babel", Ficciones, p. 89.

23 "Pierre Menard...", pp. 48 y 53.

${ }^{24}$ Ver Carmen del Río, "Borges' "Pierre Menard" or where is the Text?", KRQ, 25 (1978), 459-469, y, para una interpretación particularmente original del cuento, John Incledon, "La obra invisible de Pierre Menard"', RevIb, 43 (1977), 665-669, cuya tesis es que Menard destruyó las variantes de su escritura del Quijote - las cuales expresan el concepto de la 
del único lector del Quijote de Menard comparando su sentido al del - qué remedio - original, apuntan, cuando no se ignora su carácter irónico, según les sucede tan a menudo a los críticos de Borges respecto a su humor, a la verdadera intención de la narración, la cual introducen sabrosamente los comentarios del autor comparando los textos idénticos de Cervantes y de Menard, y elogiando la mayor sutileza del de éste.

Borges concluye que Menard "(acaso sin quererlo) ha enriquecido mediante una técnica nueva el arte detenido y rudimentario de la lectura: la técnica del anacronismo deliberado y de las atribuciones erróneas. Esa técnica de aplicación infinita nos insté a recorrer la Odisea como si fuera posterior a la Eneida [...] Esć técnica puebla de aventura los libros más calmosos. Atribuir a Louis Ferdinand Céline o a James Joyce la Imitación de Cristo, ¿nc es una suficiente renovación de esos tenues avisos espiritua les?" 25 Este tesoro de posibilidades lúdicas basado en la aboli ción de la autoría se repite en "Tlón...": "Es raro que los li bros estén firmados. No existe el concepto del plagio [...] Li crítica suele inventar autores: elige dos obras disímiles -el Ta Te King y las 1001 Noches, digamos - las atribuye a un mism escritor y luego determina con probidad la psicología de ese inte resante homme de lettres'" 26 . Estos comentarios nos invitan a n tomar la empresa de Menard tan en serio como él mismo lo hace según es típico de eruditos. Cuando al final de "Pierre Me nard", Borges, con un gesto muy característico suyo, borra ' sentido al que parecía dirigirse el texto (probar la existencia d un autor único impersonal), para poner en su lugar los juegc con los que el lector de Menard (al igual que los habitantes c Tlón) combate el tedio de la crítica literaria, está haciendo un cr mentario irónico sobre los límites del teorizar y del pensamien abstracto. Re-escribir el Quijote es un modo de negar la posibil dad de escribir sobre él con algún resultado. Que es la razón pr la que el crítico Menard prefiere a una crítica negativa (en su c so, pues no le gusta) del libro mayor de Cervantes, re-escribirl

Ahora bien, ¿por qué el Quijote? ¿Por qué escoge Menard p ra probar su tesis entre todas las obras que no le gustan demasi

escritura como memoria-, conservando sölo las páginas que coincidían c el original, para ocultar así las revolucionarias implicaciones de su descuk miento respecto a la identidad de memoria y escritura.

25 “Pierre Menard...", p. 56.

26 “"Tlön...", p. 27. 
do el Quijote, una obra sinceramente admirada por Borges y sobre la cual había ya escrito e iba a escribir paǵinas muy lúcidas analizando esa admiración? ¿Revelará quizá el objeto de la empresa de Menard algo en cuanto a la relación de Borges con el Quijote, algo que las páginas críticas ocultan?

Repasemos muy brevemente la historia de la relación de Borges con el Quijote. En su "Ensayo autobiográfico"' de 1970, Borges dice que leyó primero el Quijote en inglés y que cuando más tarde lo leyó en el original le pareció una mala traducción ${ }^{27}$, comentario del cual se retracta en el curso de una entrevista una década después, reconociendo que leyó primero el Quijote en castellano ${ }^{28}$. El libro, de cualquier modo, le causó un gran impacto, según prueba el que su primer cuento, escrito a los seis o siete años, fuese "a rather nonsensical piece", "La visera fatal", en castellano ${ }^{29}$ y en imitación, seguramente, del episodio de la visera de don Quijote $(\mathrm{I}, \mathrm{l})^{30}$.

Borges leyó pues el Quijote por primera vez, seguramente en una versión abreviada ${ }^{31}$, de niño; su primer cuento salió directamente de esa lectura: en él imitaba el estilo de Cervantes y la materia misma del Quijote. La razón principal por la que "Georgie" — según llamaba su familia al escritor- quería escribir un "romance after the manner of Cervantes",32, es que se daba perfecta cuenta de la importancia del Quijote como la obra maestra de la literatura española, el único, de hecho, entre los textos

27 "An Autobiographical Essay", The Aleph and Other Stories, 1933-1969, E.P. Dutton, New York, 1978, p. 209 [1 ${ }^{\text {a }}$ ed. 1970].

${ }^{28}$ Borges at Eighty: Conversations, ed. Willis Barnstone, Indiana University Press, Bloomington, 1982, p. 124.

29 "An Autobiographical Essay", p. 211.

30 En las entrevistas con RICHARD BURGIN (Conversations with Jorge Luis Borges, Souvenir Press, London, 1968; Conversaciones con... Taurus, Madrid, 1974), Borges cuenta que después de leer un capítulo o dos del Quijote trató de escribir en castellano antiguo (Conversaciones, p. 26). En la misma serie de entrevistas Borges describe el afecto que lo une a Cervantes, "uno de los pocos escritores españoles que puedo imaginarme [...] Sé, por ejemplo, cómo pediría disculpas por algunas de las cosas que ha escrito. Cómo no se tomaría a sí mismo demasiado en serio" (p. 146). Cervantes lo atrae no sólo como escritor, sino como hombre; lo que siente por el Quijote no le suele suceder con libros españoles o italianos, pero sí con ingleses y norteamericanos (ibid.). Ver mi "El Quijote según Borges", sobre ésta y otras entrevistas en las que Borges describe sus opiniones sobre Cervantes y el Quijote.

31 Quizá El Quijote para la juventud, Garnier, Paris, 1877. Ver “El Quijote según Borges", n. 20.

32 “An Autobiographical Essay”, p. 211. 
que la constituyen, que se parangona con las épicas homéricas, la Divina Comedia, las tragedias de Shakespeare o el Fausto de Goethe en cuanto obra que todo hombre educado se espera que conozca.

Borges se crió en un hogar en el que se hablaba inglés normalmente, pues era la lengua de la abuela paterna, quien vivía con los Borges. Bajo su guía y la de una institutriz inglesa, Borges adquirió un dominio casi perfecto del inglés. Cuando nos dice que el Quijote original le pareció inferior a su versión inglesa, y que leyó ésta antes, está demostrando una preferencia por el inglés respecto a su lengua materna. Es menester, sin embargo, que distingamos, situándolos en la perspectiva adecuada los unos respecto a los otros, los varios factores psicológicos e ideológicos que resultan en la Weltanschauung de Borges. Y también que evitemos exagerar la importancia de Fanny Haslam (la madre de Jorge Guillermo Borges, el padre del escritor) en el desarrollo de su nieto.

Borges sentía una enorme admiración por su padre, un hombre de gran cultura que fue moldeando desde muy temprano e. intelecto y los gustos literarios de su hijo. La sangre inglesa de su padre debió fortalecer la admiración que Borges sentía por él pues lo ligaba biológicamente a una gran cultura. Borges padre tenía acceso directo, a través de la lengua que le había enseñadc su madre, lo mismo que a su nieto, a la literatura producida po esa cultura. El ser medio inglés debía hacer a su padre a los ojo: de Borges incluso más civilizado y culto de lo que era natural mente, afirmando su superioridad intelectual respecto a otros ar gentinos, incluida su esposa. A pesar de que la madre de Borges Leonor Acevedo, provenía de una familia muy distinguida $d_{i}$ Buenos Aires, rica en patriotas y poetas, su bagaje cultural le pa recía a su hijo, por comparación con el del padre, pobre, inclusı primitivo ${ }^{33}$. Iba a ser, no obstante, la familia materna, así comı la ascendencia paterna del padre, las que darían al joven Borge el sentido de orgullo en su nacionalidad que demuestra en tanta obras, el cual lo ayudaría a establecer esas afinidades con seg mentos de la historia de la propia familia esenciales para cimer tar una perspectiva de uno mismo. Esto es algo que no podía pre porcionarle la familia de la abuela inglesa, la cual no estab presente en el medio donde se formó, y era, además, de orige

33 Rodríguez Monegal, "Borges, the Reader", Diacritics, 1974, nún 4, pp. $47-48$. 
pequeñoburgués (Fanny Haslam emigró a la Argentina durante el último cuarto del xix para reunirse con una hermana casada con un comerciante italojudío) $)^{34}$, en tanto que los Acevedo, los Laprida, etc., provenían del estrato superior de la burguesía porteña.

Obviamente, Borges niño debe haber sentido cierta tensión y hasta algún conflicto psicológico en relación con las dos culturas y códigos lingüísticos a los que estaba constantemente expuesto ${ }^{35}$. Más no hay por ello que exagerar la importancia de la lengua y la literatura inglesas en la educación de Borges; no hay que aceptar sin cuestionarlo su propio testimonio, el cual expresa su desmedida anglofilia. Cuando el futuro escritor tenía quince años, los Borges se trasladaron a Europa, permaneciendo en Ginebra hasta 1919. Allí Borges asistió al liceo, recibiendo en él una educación francesa; aprendió latín, que era entonces esencial en el curriculum escolar, y, por su cuenta, alemán ${ }^{36}$. Fue la abuela materna la que acompañó a los Borges a Europa, donde sólo más tarde se les unió la abuela inglesa ${ }^{37}$. Nótese también que entre los libros que llevaban consigo en su viaje los Borges iban los clásicos argentinos ${ }^{38}$. Estos factores no niegan que el inglés fuese

34 “An Autobiographical Essay", p. 204.

${ }^{35}$ Ver al respecto EMIR Rodríguez Monegal, "Borges: the Reader as Writer" (Prose for Borges, eds. Charles Newman and Mary Kinzie, Northwestern University Press, 1972, pp. 96-137); “Borges, the Reader"; y Jorge Luis Borges. A Literary Biography, E.P. Dutton, New York, 1978.

${ }^{36}$ Estas dos últimas lenguas parecen haber atraído a Borges más que el francés, el cual, aunque reconoce que tiene "a fine literature despite its fondness for schools and movements", dice que le parece feo, agregando que "Things tend to sound trivial when they are said in French. In fact, I even think of Spanish as being the better of the two languages, though Spanish words are far too long and cumbersome", lo que sabe muy bien por tener que lidiar, como escritor en castellano, con sus desventajas ("An Autobiographical Essay", p. 217). (Tampoco le ha gustado nunca París: ibid., p. 214.) Nótese, sin embargo, que en el cuento "El otro", de El libro de arena (1975), Borges cita una "famosa línea" de Hugo ("L'hydre-univers tordant son corps écaillé d'astres"), la cual su interlocutor escucha con "casi temeroso estupor", y reconoce que nunca podría "escribir una línea como esa", de lo que concluye el narrador que "Hugo nos había unido" (El libro de arena, p. 18). Historia de la noche, de 1977, contiene un poema, "A Francia", donde Borges afirma que aunque "Me desviaron otros amores / y la erudición vagabunda [...] no dejé nunca de estar en Francia / y estaré en Francia cuando la grata muerte me llame", y cita a continuación a Verlaine, Victor Hugo, Montaigne. la Chanson de Roland. (Historia de la noche, Emecé, Buenos Aires, p. 111).

37 "An Autobiographical Essay", pp. 214 y 215.

${ }^{38}$ Facundo, Martín Fierro, Amalia, la Historia argentina de Vicente Fidel Ló- 
siempre para Borges "el certificado de cultura"'39, como lo demuestra el que diga elogiando a su madre que a partir del momento en que aprendió inglés, leyó principalmente en esa lengua $^{40}$. $Y$ es también cierto que el interés de Borges en el inglés se convirtió con el paso del tiempo en una pasión casi fanática que lo hacía despreciar, a ratos, su lengua materna, por pobre, y desear que el inglés, que se siente "unworthy to handle", hubiese sido su "birthright" 41.

A pesar de lo cual, no se debe concluir del contacto de Borges con el inglés desde tempranísima edad que esa lengua fuese la sola llave del mundo de la lectura y la escritura, de la imaginación la literatura y en última instancia la cultura ${ }^{42}$. Lo que sucede e: algo más complejo. Algunos años después de su regreso a Bueno: Aires, y tras algunos devaneos con ideas radicales ${ }^{43}$, la concien cia de Borges de su propia cultura y de sí mismo en relación cor ella cristaliza en una ideología que va a experimentar muy poco: cambios a partir de allí. Esto ocurre hacia la época de la crisi institucional de 1930, cuyos efectos se continúan sintiendo en 1: Argentina.

A partir de ese momento Borges va a ver a ésta, y por exten sión a Latinoamérica, como un mundo intrínsecamente caótic y bárbaro, barbarie a la que se opone e incluso ataca, eterna infructuosamente, gente como los antepasados del propio escri

pez, varios libros de Eduardo Gutiérrez, las obras de Ascasubi - algunos c cuyos versos gauchos Borges recitó "loud and bold" ("An Autobiographic: Essay", p. 214) en el anfiteatro romano de Verona durante una visita a ciudad en 1915- y otras obras de Eduardo Wilde, Ramos Mejía, Lugon (Antonio Carrizo, Borges el memorioso. Coversaciones de Jorge Luis Borges con A: tonio Carrizo, F.C.E., México, 1982).

${ }^{39}$ Rodríguez Monegal, "Borges, the Reader", p. 47.

40 "An Autobiographical Essay", p. 207.

${ }^{41}$ Ibid., p. 258.

42 Rodríguez Monegal, "Borges, the Reader", p. 43.

${ }^{43}$ Durante su estancia en España Borges escribió un libro de ensayos terarios y políticos, y un libro de poemas en elogio de la revolución rusa, hermandad humana y el pacifismo, titulado "Los salmos rojos" o "Los $r$ mos rojos", algunos de cuyos poemas fueron publicados en revistas. El m nuscrito del primer libro fue destruido por Borges al llegar a Buenos Aire al no hallar quien lo publicase; el segundo libro lo destruyó en vísperas de partida de España ("An Autobiographical Essay", p. 223). El poema "R sia", de estilo ultraísta, fue incluido en Índice de la nueva poesía americana, pr de Alberto Hidalgo, Vicente Huidobro y Jorge Luis Borges (Sociedad de F blicaciones, Buenos Aires, 1926). También se menciona "Los salmos rojo en "El otro". (El libro de arena, pp. 15-16). 
tor (los Laprida y los Suárez de poemas memorables) ${ }^{44}$, y también él mismo. Esta visión, a la vez que afirma el sentido de identidad de Borges con su familia (principalmente materna), subraya su aislamiento respecto a su propio país y al mundo latinoamericano. La consecuencia última de todo ello será una concepción abiertamente reaccionaria de la historia, la cual identifica a Latinoamérica con una barbarie que no puede ser vencida y transformada en civilización, y a ciertos hombres - definidos en parte como intelectuales, pero principalmente desde el punto de vista de su clase social, que es la de Borges - con la defensa de la civilización, es decir, de un sistema de valores culturales y sociales característicamente europeos y, para Borges, específicamente británicos ${ }^{45}$.

Es a esa altura de la construcción ideológica que la relación de Borges con la cultura inglesa viene a desempeñar su papel más importante, proveyéndolo no de un pasado, y tampoco de una identidad que sólo puede porporcionarle su argentinidad tan firmemente sentida, sino más bien de un sentimiento de falta, de algo que pudo haber sido y no fue. El ser una cuarta parte inglés intensifica el sentimiento de aislamiento de Borges en relación con su propio medio bárbaro. Paradójicamente, también estrechá su vínculo con él: al igual que nunca podrá ser él totalmente inglés, tampoco podrán la Argentina y Latinoamérica alcanzar el nivel de orden social, de desarrollo cultural y de statu respecto a las demás naciones del que goza Inglaterra, lo mismo que su admirado heredero, Estados Unidos. Naturalmente que esas conclusiones expresan cierta verdad, sólo que al convertirlas en un sentimiento de pérdida irreparable, Borges se encierra en un callejón sin salida respecto al futuro tanto político como cultural de la sociedad de la que es, sin embargo, parte integral.

Cuando afirma que leyó el Quijote primero en inglés que en castellano, y que le sonaba y sigue sonando mejor en esa lengua, Borges revela un deseo inconsciente de asignar ese texto reverenciado, el más importante de las literaturas hispánicas, y cuya lectura fue motivo de gran placer para él a partir de la primera vez que lo leyó, a aquella de sus "dos culturas" que le parece la más

${ }^{44}$ Ver, respectivamente, "Poemạ conjetural" y "Página para recordar al coronel Suárez, vencedor en Junín", en Poemas 1923-1953, Emecé, Buenos Aires, 1954, pp. 155 y 161.

${ }^{45}$ Ver mi "La intención política en la obra de Borges: hacia una visión de conjunto", CuH, 121 (1980), 170-198. 
rica y compleja, la que, por lo tanto, merece mejor esa obra. Mas como el Quijote pertenece al cabo a su otra cultura, la hispanoargentina y dominante en él, Borges desarrollará respecto a la obra primada una relación ambivalente de amor y desprecio (recuérdese lo que dice sobre el estilo de Cervantes, y sobre la Primera parte) paralela a la que siente por la Argentina y su cultura.

Menard, el crítico y poeta de segunda fila cuyo más alto logro, aquel al que dedicó el más continuado e intenso de sus esfuerzos, fue re-escribir el Quijote, se nos aparece así como una imagen de Borges según se ve él a sí mismo en relación con Don Quijote, obra que, como máximo representante de la cultura hispánica, participa de la barbarie que Borges, por ser el país bárbaro donde le tocó nacer parte de esa cultura, hace consustancia a ella.

Don Quijote es un texto que Borges ha leído varias veces desd la infancia, y cuya importancia acepta de lleno, pues como escritor atraído desde siempre por el género novela, entendería tem. prano lo que esa obra representa en términos de la fundación de género (esto quedaría confirmado por su lectura de la crítica de Quijote y de la historia y la teoría literarias). Para 1939, la fechi de "Pierre Menard", Borges se ha distanciado de la literatur: española - de cuyo movimiento contemporáneo sólo estuvo a tanto durante su estancia en España antes del regreso a la Argen tina en 1921-, según lo prueban las cada vez más escasas men ciones de autores españoles en sus notas críticas después del libr rechazado Inquisiciones ${ }^{46}$. En ese momento crucial de su vida cuando su conservadurismo se define, coincidiendo con el finc de su cuarta década (nació en 1899), Borges siente la necesidaı de definir la posición dentro del canon literario de ese texto qu tanto lo atrae, y también de definirse a sí mismo respecto a él

Menard, quien al igual que Borges en 1939, no había escrit aún nada que lo inmortalizase, no quiere escribir una nueva nc vela, es decir, un nuevo Quijote, en la medida en que éste es c patrón del género. Pero el erudito crítico no se limita a esa dec sión negativa respecto al género novela, criticado por Borges e su manifestación preferida, la novela de caracteres ${ }^{47}$, y tampoc a relegar a Don Quijote a la categoría de las obras innecesaria:

${ }^{46}$ Inquisiciones, Proa, Buenos Aires, 1925, contiene ensayos sobre Qu vedo, Torres Villarroel, Unamuno, Cansinos Assens, Gómez de la Serna.

47 Ver el prólogo a La invención de Morel, de Adolfo Bioy Casares (194C donde se acusa a la "novela característica, "psicológica"" de "informe" falta de orden, y de pretender que olvidemos "su carácter de artificio verba 
Menard se entrega a la tarea de probar que puede re-escribir el Quijote. Su propósito declarado es demostrar la unidad de toda la producción literaria. Hay, sin embargo, otra razón para su empresa, menos abstracta y más importante para Borges: desposeer a la literatura española de su obra cumbre. $\mathrm{Al}$ apropiarse ésta en nombre de ese Espíritu Universal autor de todas las obras, aquélla tendrá que renunciar a su pretensión de igualarse a otras literaturas universales. Al mismo tiempo, la demostración de Menard debe probar más allá de cualquier duda, como consecuencia de su habilidad de recrear palabra por palabra un texto que no le gusta y recuerda vagamente (su tarea se habría facilitado de tratarse de una obra admirada, pero ello disminuiría la validez de la prueba, sugiriendo que quizá sólo es posible re-escribir los textos que amamos) cuánto erramos dándole tanta importancia.

Pero el proyecto de Menard fracasa, según lo indican las bromas con las que concluye el cuento. Frente a los esfuerzos del supercivilizado crítico para hacer suya esa obra que lo trae sin cuidado, Don Quijote como creación de Cervantes, y con él la literatura española, la cultura hispánica, el continente bárbaro donde vive el corresponsal de Menard, se reconstruyen con más fuerza que nunca. La barbarie es, desgraciadamente, indestructible. Sólo resta ante ella para el intelectual, como arma de combate, la ironía.

Para concluir, habrá que examinar brevísimamente lo que puede expresar el Quijote de Menard respecto a la relación de Borges con su padre, quien compuso varios libros: una colección de cuentos orientales, otra de ensayos, una pieza teatral sobre la desilusión de un hombre con su hijo (destruidos), una traducción de Omar Kayam y una novela, El caudillo (estos dos últimos publicados) ${ }^{48}$. Borges cuenta en su autobiografía que a partir del momento en que su padre perdió la vista - lo mismo que le sucedería a él años después-, "estuvo sobreentendido que yo cumpliría el destino literario que las circunstancias le negaron a mi padre" 49 . Antes de morir, éste le dijo que quería que reescribiese su novela (cuyo argumento se inspiraba en las guerras civiles

(Adolfo Bioy Casares, La invención de Morel, Emecé, Buenos Aires, 1968, p. 12).

48 "An Autobiographical Essay", p. 211. Ver sobre El caudillo, publicada en Mallorca en 1921, Antonio Pagés Larraya, "Una extraña novela del padre de Borges", La Estafeta Literaria, 589 (junio 1976), 14-16.

49 "An Autobiographical Essay", p. 211. 
argentinas) en un estilo directo, eliminando todas las lindezas d estilo del texto, algunas de las cuales fueron contribución de si hijo durante su período ultraísta ${ }^{50}$. Al final de su memoria auto biográfica, Borges afirma que sigue proponiéndose hacer lo qu su padre le rogó: "Tengo otro proyecto que ha estado pendient por largo tiempo, el de revisar y quizá reescribir la novela de $\mathrm{m}$ padre, El caudillo, como me lo pidió él hace años. Llegamos inclu so a discutir muchos de los problemas relacionados con ello, y m gusta pensar en esa tarea como en un diálogo que se continúa en una verdadera colaboración'"51.

Las circunstancias en que fue escrito "Pierre Menard" si gieren la existencia de una conexión con esa promesa de Borg، a su padre. El mismo año en que éste murió, sufrió su hijo u accidente que lo puso al borde de la muerte (básicamente el mi mo accidente que mata al protagonista del cuento "El sur" Preguntándose al comenzar a recuperarse si sería aún capaz c escribir, Borges decidió no tratar de componer otra reseña con las muchas que había escrito hasta entonces, pues si fallaba sentiría destruido intelectualmente, en tanto que si ensayaba : go que jamás había hecho antes y fallaba, ese fracaso no afectaría tanto, preparándolo para la revelación final. Así q1 decidió escribir un cuento, y el resultado fue "Pierre Menard".

Es concebible que Borges viese sus sufrimientos de esas sem nas como un castigo por no haber cumplido las grandes espera zas que tenía su padre en su carrera literaria, y más específic mente por no haber reescrito El caudillo. De ser así, el cambio género y estilo que representa "Pierre Menard" sería parad: mático de una liberación de la influencia paterna a través de búsqueda de una nueva identidad artísitca, y constituiría ta bién una confirmación de que Borges no iba a re-escribir la nor la de su padre y, continuando la vocación frustrada de éste, cc vertirse en novelista.

Mas como sucede siempre con Borges, las cosas se complic

50 "I recall giving him some quite bad metaphors, borrowed from German expressionists, which he accepted out of resignation" ("An $\mathrm{Al}_{1}$ biographical Essay", p. 219). Véase al respecto Antonio CARrizo, Borge memorioso, p. 20. p. 20

51 "An Autobiographical Essay", p. 259. Ver también Carrizo, op.

52 “An Autobiographical Essay", pp. 242-243. En Luis Harss, Intc Mainstream. Conversation with Latin American Writers (Harper, New York, 19 dice Borges que fue "Tlön...", el cuento que escribió al restablecerse (p. 1 
en cuanto las examinamos de cerca. "Pierre Menard" no es el primer cuento de Borges en lo que él caracteriza como su nuevo estilo. "El acercamiento a Almotásim" fue escrito en 1935 y, lo mismo que "Pierre Menard", está compuesto como una reseña y juega también con lo fantástico. A lo sumo, "Pierre Menard" representa una afirmación de la nueva manera. Hay también que evitar la magnificación del papel de padre de Borges en la carrera y en la vida de su hijo. Es cierto que esos textos de Borges que tratan de un personaje que es la creación o el sueño de otro ("Las ruinas circulares", "El gólem"), o de las relaciones sexuales como una actividad que no le concierne ("La secta del Fénix') sugieren, cuando se los relaciona con lo que Borges ha escrito o dicho en entrevistas sobre su relación con su padre, una dependencia de carácter neurótico respecto a él ${ }^{53}$. Iba a ser, no obstante, su madre la que desempeñaría el papel más largo (murió a los noventa y nueve años) e importante en la vida de Borges, pues no sólo se ocupaba de los detalles materiales de la vida del escritor, sino que le leía e incluso lo ayudaba con ideas y sugerencias ${ }^{54}$. La admiración de Borges por su madre es similar a la que siente por su padre, y aunque no la pinta como una intelectual, al modo que hace con aquél, elogia su gusto literario, su talento como traductora de inglés, y cuenta que era una lectora insaciable (como la abuela Haslam) ${ }^{55}$.

"And yet, and yet", como escribió en una ocasión Borges ${ }^{56}$, creo que estamos justificados en ver, detrás de ese "game of shifting mirrors" (subtítulo de la novela inventada "The approach to Al-Mu'tasim") ${ }^{57}$ que construye Borges en "Pierre Menard" para sugerir y ocultar al mismo tiempo sus ideas y sentimientos más profundos, una relación entre su propia carrera y la de su padre con la de Menard, y más en concreto con su proyecto respecto al Quijote, todas ellas vistas como inútiles, especialmente en relación con la novela, ya que la re-escritura por $\mathrm{Me}$ nard de la novela-padre va a pasar desapercibida. Al escribir

53 Emir Rodríguez Monegal, "Borges": the Reader as Writer", TriQuarterly, 25 (1972), 125-143.

54 "An Autobiographical Essay", p. 207. Cuenta Borges que fue su madre quien le proporcionó las palabras que necesitaba para concluir su cuento "La intrusa" ("Commentaries", The Aleph, p. 278; Antonio Carrizo, $\alpha p$. cit., p. 30).

55 “An Autobiographical Essay", pp. 206 y 207.

56 " "Nueva refutación del tiempo", Otras inquisiciones, p. 187.

57 "El acercamiento a Almotásim", Ficciones, p. 36. 
sobre el proyecto fracasado de Menard, Borges está aludiendo a sus propios encontrados sentimientos respecto al Quijote y Cervantes, la literatura española, su propia cultura y la personalidad literaria y psicológica de su padre.

Cervantes y su obra maestra, la primera novela moderna. están percibidas como un obstáculo en la carrera de cualquier novelista - Borges padre lo mismo que su hijo si éste decide se guir las huellas paternas, empezando por re-escribir El caudilloen cuanto constituyen un modelo cuyo éxito parece imposible su perar. De suerte que Menard tendrá que desindividualizar e Quijote: cualquier europeo educado es capaz de re-escribir cual quier obra, incluso Don Quijote. De ser probada, la tesis de $\mathrm{Me}$ nard tendría un efecto demoledor sobre la posición de Don Quijot en el canon. Sólo después de "matar" de ese modo al Quijote, : su autor, a la literatura de que es abanderado, podrá quedar Bor ges, su devoto lector, libre para escribir, en primer lugar, sus fic ciones -en lugar de novelas (recuérdese cómo en el prólogo Ficciones nos dice que puesto que una idea puede expresarse e: unos pocos renglones, es inútil escribir cientos de páginas par exponerla).

La capacidad intelectual de Menard queda probada por c haber sido capaz de escribir, bien que después de fatigosos borrc dores, esos capítulos del Quijote cuya existencia demuestra $\mathrm{s}$ igualdad con Cervantes y que ninguna obra es original. Mi como nadie excepto su corresponsal, especie de hijo espiritua reconoce el triunfo de Menard, mientras que el público va descartar su obra maestra como una mera copia de la de Cervar tes, su proyecto constituye un fracaso tanto como un triunfo; mismo que los logros novelísticos de Borges padre, de quien M nard es quizá una imagen. El resultado final es que Borges hi no tendrá que sujetarse a las aspiraciones de su padre, no tend que seguir sus huellas.

"Pierre Menard" es el primero entre los textos "canónicos de Borges, incluidos los ensayísticos, sobre el Quijote ${ }^{58}$. En él r presenta Borges cuestiones que le urgía definir a sus cuaren años. Mas como era de esperar de la complejidad de aquélla nada definitivo resulta de ese estupendo relato respecto a la res

\footnotetext{
${ }^{58}$ Ya se mencionó antes el ensayo "La conducta novelística de Cerví tes", de El idioma de los argentinos, de 1928. Sobre este y otros textos críti anteriores a 1940, ver mis dos artículos bibliográficos.
} 
lución de los conflictos que venimos examinando. El tono final es irónico y tiene mucho de sorna.

Es con posterioridad a "Pierre Menard" cuando Borges escribirá sus mejores páginas sobre el Quïjote, donde demuestra con creces que ama ese texto y que lo comprende, al igual que su importancia para el desarrollo de la novela moderna, la de caracteres, género que obviamente lo atrae, según lo muestran tantos de sus cuentos, pero que jamás ha emprendido sino en la medida en que esos cuentos la tocan. Al igual que Menard tampoco escribió sino dos capítulos y medio de su Quijote.

Julio Rodríguez-Luis State University of New York at Binghamton 
